\title{
FORMULASI DAN EVALUASI SIFAT FISIK FACIAL WASH GEL EKSTRAK KULIT BUAH NAGA MERAH (Hylocereus polyrhizus) DENGAN GELLING AGENT CARBOPOL
}

\author{
Nia Yuniarsih, Fauzi Akbar, Icha Lenterani, Farhamzah \\ Fakultas Farmasi, Universitas Buana Perjuangan Karawang, Karawang, Jawa Barat, \\ Indonesia. \\ *Penulis Korespondensi: nia.yuniarsih@ubpkarawang.ac.id
}

\begin{abstract}
ABSTRAK
Kulit buah naga (Hylocereus polyrhizus) mengandung senyawa flavonoid yang berfungsi sebagai antioksidan. Antioksidan dalam kosmetik digunakan untuk mencegah penuaan dini. Facial wash merupakan salah satu cara untuk membersihkan sel kulit mati, kotoran, minyak, dan kosmetik. Penelitian ini bertujuan memformulasi facial wash gel ekstrak kulit buah naga dengan memvariasikan konsentrasi carbopol $(1 \%, 1,5 \%$, dan $2 \%)$ sebagai basis gel. Hasil uji organoleptis menunjukkan parameter aroma, warna tidak berbeda nyata antar formula, perbedaan konsistensi bentuk pada sediaan terihat pada formulasi 1 (kental) sedangkan formulasi 2 dan 3 (agak kental). Hasil evaluasi menunjukkan formula 1 dengan carbopol $1 \%$ menghasilkan facial wash gel yang paling baik dibandingkan dengan formula 2 dan 3. Evaluasi sediaan didapatkan bahwa perbedaan konsentrasi carbopol berpengaruh pada daya busa, $\mathrm{pH}$ dan viskositas. Hasil evaluasi dianalisis menggunakan one way ANOVA menunjukkan nilai $\alpha<0,05$ pada evaluasi daya busa, $\mathrm{pH}$ dan viskositas.
\end{abstract}

Kata kunci: Ekstrak, Facial wash, Carbopol, Kulit buah naga 


\title{
FORMULATION AND PHYSICAL STABILITY TEST OF FACIAL WASH GEL FROM DRAGON FRUIT (Hylocereus polyrhizus) PEEL EXTRACT WITH CARBOPOL GELLING AGENT
}

\begin{abstract}
Dragon fruit peel (H. polyrhizus) contains flavonoid compounds that function as antioxidants. Antioxidants in cosmetics are used to prevent premature aging. Facial wash is a way to clean dead skin cells, dirt, oil, and cosmetics. This study aims to formulate dragon facial wash gel dragon fruit peel extract by varying the concentration of carbopol $(1 \%, 1.5 \%$, and $2 \%)$ as the base gel. The results of the organoleptic test showed that the aroma and color parameters were not significantly different between the formulas, the differences in the shape of the dosage were seen in formulation 1 (viscous) while formulations 2 and 3 (slightly viscous). The evaluation results showed that formula 1 with $1 \%$ carbopol produced the best facial wash gel compared to formulas 2 and 3 . The evaluation of the preparations showed that the difference in carbopol concentration had an effect on foam power, $\mathrm{pH}$ and viscosity. The evaluation results were analyzed using one way ANOVA showing a value of $\alpha$ $<0.05$ on the evaluation of foam power, $\mathrm{pH}$ and viscosity.
\end{abstract}

Keywords: Extracts, Facial wash, Carbopol, Dragon fruit peel

\section{PENDAHULUAN}

Proses penuaan merupakan suatu proses fisiologis yang terjadi pada semua organ tubuh manusia, termasuk kulit. Penuaan kulit terjadi oleh beberapa faktor salah satunya yang paling mendasar yakni radikal bebas. Radikal bebas adalah suatu atom atau molekul yang sangat reaktif dengan elektron yang tidak memiliki pasangan (Winarsih, 2007). Pembersihan wajah menggunakan facial wash merupakan salah satu cara untuk membersihkan sel kulit mati, kotoran, minyak, dan kosmetik. Facial wash juga dapat dijadikan langkah awal dalam perawatan kulit sehari-hari.

Sabun merupakan tipe surfaktan yang dapat mengurangi tegangan permukaan dan tegangan antarmuka, serta memiliki sifat penyabunan, dispersibilitas, emulsifikasi, dan pembersih (Mitsui, 1997). Kemampuan sabun tersebut dapat dimanfaatkan untuk membersihkan wajah dari paparan debu, polusi, kotoran, serta minyak di wajah yang dapat menginisiasi timbulnya jerawat. Kulit buah naga mengandung vitamin $\mathrm{C}$, vitamin $\mathrm{E}$, vitamin $\mathrm{A}$, alkaloid, terpenoid, flavonoid, tiamin, niasin, piridoksin, kobalamin, fenolik, karoten, dan fitoalbumin (Jaafar et al., 2009). Menurut penelitian $\mathrm{Wu}$, et al., keunggulan dari kulit buah naga yaitu kaya polifenol dan merupakan sumber antioksidan. Kulit buah naga akan diformulasikan menjadi bentuk sediaan facial wash gel sehingga mempermudah penggunaannya $(\mathrm{Wu}$ et al., 2006) 
Carbopol merupakan gel hidrofilik, sehingga mudah terdispersi dalam air dan dalam konsentrasi kecil dapat berfungsi sebagai basis gel dengan kekentalan yang cukup pada pH 6-11 (Rowe et al, 2009). Keuntungan pemakaian carbopol dibandingkan dengan bahan lain adalah sifatnya yang mudah didispersikan oleh air dan dengan konsentrasi kecil yaitu 0,050-2,00\% mempunyai kekentalan yang cukup sebagai basis gel (Melani et al, 2005). Berdasarkan uraian di atas, maka dilakukan optimasi yang bertujuan untuk mengetahui komposisi gelling agent yang optimum yaitu menghasilkan gel dengan stabilitas terbaik. Pada penelitian ini digunakan carbopol sebagai gelling agent untuk facial wash gel dari ekstrak kulit buah naga merah (H. polyrhizus).

\section{METODE PENELITIAN}

Alat

Neraca analitik (Adam PW254), blender, mesh, viskometer (Lamy Rheologi First Touch 15.04T. F016), pH meter (NeoMet pH-240L GJ-7726), magnetic stirer IKA C- MAG HS 7), homogenizer (WiseTis HG-15D), oven, batang pengaduk, alumunium foil, dan labu ukur.

\section{Bahan}

Ekstrak kulit buah naga, beras merah, carbomer, nipagin, Na4EDTA, gliserin, propylen glycol, sodium lauryl sulfate, trietanolamin, citric acid, parfum, pewarna, dan aquadest.

\section{Prosedur Penelitian}

Tabel 1. Formula facial wash gel kulit buah naga

\begin{tabular}{lcccl}
\hline \multirow{2}{*}{ Bahan } & \multicolumn{3}{c}{ Konsentrasi (\%) } & \multirow{2}{*}{ Kegunaan } \\
\cline { 2 - 4 } & F1 & F2 & F3 & \\
\hline Ekstrak kulit buah naga & 8 & 8 & 8 & Zat aktif \\
\hline Beras merah & 1,2 & 1,2 & 1,2 & Scrub \\
\hline EDTA-4Na & 0,1 & 0,1 & 0,1 & Chelating agent \\
\hline Gliserin & 2 & 2 & 2 & Pembasah \\
\hline SLS & 2,5 & 2,5 & 2,5 & Foaming agent \\
\hline Propylen glycol & 1 & 1 & 1 & Pelarut pengawet \\
\hline Nipagin & 0,2 & 0,2 & 0,2 & Pengawet \\
\hline Pewarna & 0,1 & 0,1 & 0,1 & Pewarna \\
\hline Parfume & 0,1 & 0,1 & 0,1 & Pewangi \\
\hline Carbophol & 1 & 1,5 & 2 & Gelling agent
\end{tabular}




\begin{tabular}{lrrrl}
\hline TEA & 3 & 3 & 3 & Alkalizing agent \\
\hline Citric acid & 1 & 1 & 1 & Buffering agent \\
\hline Aquadest & ad 100 & ad 100 & ad 100 & Pelarut
\end{tabular}

(Manish et al., 2019).

Tabel 2. Optimasi komposisi carbopol pada formula facial wash gel ekstrak kulit buah naga

\begin{tabular}{cc}
\hline & Konsentrasi (\%) \\
\cline { 2 - 2 } Formula Optimasi & Carbophol \\
\hline 1 & 1 \\
2 & 1.5 \\
3 & 2 \\
\hline
\end{tabular}

\section{Pembuatan Dragon Facial Wash}

Aquadestilata, nipagin, EDTA-4Na glycerine dan propylene glycol di homogenkan dengan magnetic stirrer lalu tambahkan SLS, panaskan larutan hingga suhu $40^{\circ} \mathrm{C}$, tambahkan propylen glycol, parfum, asam sitrat, ekstrak kulit buah naga, scrub beras merah sedikit demi sedikit sampai homogen, tambahkan carbopol dan TEA sampai homogen.

\section{Evaluasi Sediaan}

1. Skrining Fitokimia

Skrining fitokimia dilakukan untuk mengetahui dan mengindentifikasi senyawa kimia yang terkandung dalam ekstrak kulit buah naga $(H$. polyrhizus). Skrining fitokimia yang dilakukan yaitu uji alkaloid, flavonoid, saponin, tannin, polifenol, steroid, terpenoid, alkaloid.
2. Uji Organoleptik

Uji organoleptis dilakukan secara visual, komponen yang dievaluasi meliputi bau,warna, bentuk, dan tekstur sediaan krim.

3. Uji $\mathrm{pH}$

Pengukuran nilai $\mathrm{pH}$ pada facial wash gel menggunakan $\mathrm{pH}$ meter, sampel ditimbang sebanyak 3 gr diencerkan dengan $30 \mathrm{ml}$ aquades dalam beaker glass. Elektroda dicelupkan dalam larutan tersebut. Nilai $\mathrm{pH}$ yang stabil tertera dalam alat kemudian dicatat.

4. Uji Daya Busa

Kemampuan membentuk busa facial wash gel diukur dengan melarutkan sampel dalam air pada gelas ukur. Sampel ditimbang sebanyak 1 gr, dimasukkan ke dalam tabung reaksi, kemudian ditambahkan akuades 
sampai $10 \mathrm{ml}$, dikocok dengan membolak-balikkan tabung reaksi, lalu segera diukur tinggi busa yang dihasilkan.

Kemampuan pembentukan busa dihitung dengan mengukur tinggi busa dan stabilitas busa diukur dengan menghitung waktu busa mulai hilang. Tabung didiamkan selama 5 menit, kemudian diukur lagi tinggi busa yang dihasilkan setelah 5 menit. Tinggi busa yang terbentuk kemudian dicatat.

5. Uji Viskositas

Viskositas facial wash gel ekstrak kulit buah naga merah diukur menggunakan viskometer. Sampel diletakkan sekitar $30 \mathrm{~g}$ pada cone. Pengukuran dilakukan dengan meningkatkan laju geser dari 0.5/detik sampai 100/detik dan viskositas dibaca pada setiap putaran per menit.

\section{HASIL PENELITIAN}

\section{Skrining Fitokimia}

Tabel 3. Hasil skrining fitokimia ekstrak kulit buah naga

\begin{tabular}{|c|c|c|c|}
\hline Kandungan Kimia & Pereaksi & Hasil & Keterangan \\
\hline Flavonoid & Serbuk $\mathrm{Mg}$ dan $\mathrm{HCl} 2 \mathrm{~N}$ & + & $\begin{array}{l}\text { Terbentuknya warna } \\
\text { kemerahan }\end{array}$ \\
\hline Saponin & Aquadest & + & Menghasilkan busa \\
\hline Tanin & Gelatin $1 \%$ & - & $\begin{array}{l}\text { Tidak terdapat endapan } \\
\text { putih }\end{array}$ \\
\hline Polifenol & $\mathrm{FeCl}_{3} 1 \%$ & + & $\begin{array}{l}\text { Terbentuknya warna } \\
\text { hijau }\end{array}$ \\
\hline Streoid & $\begin{array}{l}\mathrm{HCl} \text { pekat dan } 1 \text { tetes } \\
\mathrm{H}_{2} \mathrm{SO}_{4}\end{array}$ & + & $\begin{array}{l}\text { Terbentuknya warna } \\
\text { hijau }\end{array}$ \\
\hline Alkaloid & $\mathrm{HCl}$ dan Dragendrof & + & $\begin{array}{l}\text { Tidak terdapat endapan } \\
\text { merah }\end{array}$ \\
\hline
\end{tabular}

Keterangan: (+) Ada, (-) Tidak ada. 


\section{Uji Organoleptis}

Tabel 4. Hasi uji organoleptis dragon facial wash gel

\begin{tabular}{|c|c|c|c|}
\hline Formulasi & Parameter & Hasil & Gambar \\
\hline \multirow[t]{3}{*}{1} & Warna & Ungu & \\
\hline & $\mathrm{Bau}$ & Khas Ekstrak & \\
\hline & Bentuk & ++ & \\
\hline \multirow[t]{3}{*}{2} & Warna & Ungu & \\
\hline & Bau & Khas Ekstrak & \\
\hline & Bentuk & ++ & \\
\hline \multirow[t]{3}{*}{3} & Warna & Ungu & \\
\hline & Bau & Khas Ekstrak & \\
\hline & Bentuk & + & \\
\hline
\end{tabular}

Keterangan: (+) Agak kental, (++) Kental.

\section{Uji pH Sediaan}

Tabel 5 Hasi uji pH dragon facial wash gel

\begin{tabular}{cc}
\hline Formula & pH \\
\hline I & $6,46 \pm 0,21$ \\
II & $6,99 \pm 0,01$ \\
III & $6,68 \pm 0,043$
\end{tabular}

\section{Uji Daya Busa}

Tabel 6. Hasil uji daya busa dragon facial wash gel

\begin{tabular}{cccc}
\hline Formula & Tinggi busa awal $(\mathbf{c m})$ & Tinggi busa akhir(cm) & Stabilitas busa (\%) \\
\hline I & $9,5 \pm 0,4$ & $6,5 \pm 0,5$ & $67,67 \pm 7,4$ \\
II & $8,43 \pm 1,7$ & $6,43 \pm 1,1$ & $75,83 \pm 9,23$ \\
III & $5,83 \pm 1,7$ & $4,1 \pm 0,7$ & $70,53 \pm 4,51$
\end{tabular}

Keterangan: Data merupakan nilai rata-rata \pm SD. 


\section{Uji Viskositas}

Tabel 7. Hasil uji viskositas dragon facial wash gel

\begin{tabular}{cc}
\hline Formula & Rata-rata viskositas (cPs) \\
\hline Formula I & $3523,33 \pm 345,5$ \\
Formula II & $4714,33 \pm 299,0$ \\
Formula III & $5847,33 \pm 344,9$
\end{tabular}

Keterangan: Data merupakan nilai rata-rata \pm SD.

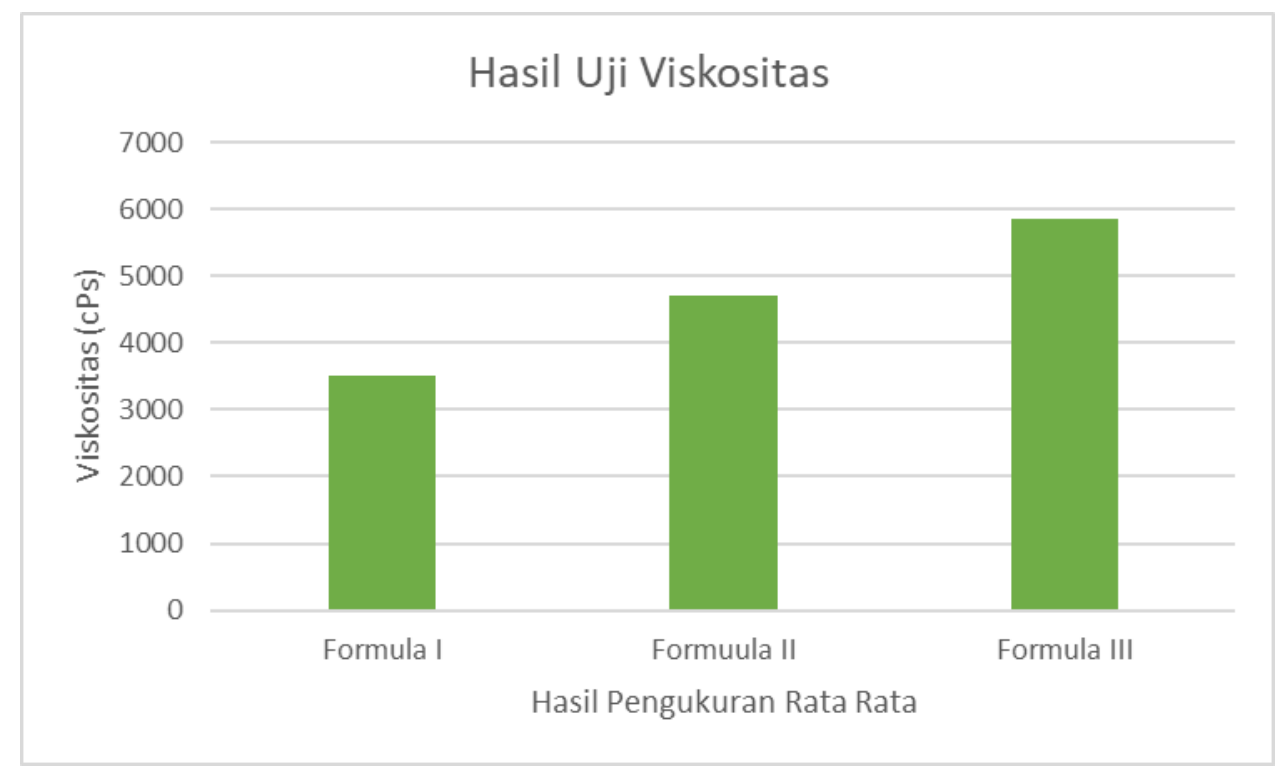

Gambar 1. Uji viskositas dragon facial wash gel.

\section{PEMBAHASAN}

Pembuatan dragon facial wash gel pada penelitian ini dilakukan dengan memvariasikan konsentrasi carbomer. Variasi konsentrasi carbomer bertujuan untuk memperoleh konsentrasi carbomer yang dapat memberikan karakteristik facial wash gel yang baik dan formula yang optimal. pengujian pertama dilakukan skrining fitokimia terhadap ekstrak kulit buah naga merah $(H$. polyrhizus), skrining fitokimia bertujuan untuk mengetahui informasi awal golongan senyawa metabolit sekunder. Selain itu juga bertujuan untuk mengetahui apakah suatu jenis tumbuhan tersebut potensial untuk di manfaatkan (Harborne, 1978). Berdasarkan dari skrining fitokimia dapat dilihat bahwa ekstrak kulit buah naga berpotensi 
memiliki beberapa senyawa metabolit sekunder yaitu flavonoid, alkaloid, saponin dan polifenol. Hasil pengamatan organoleptis dragon facial wash gel setelah 1x24 jam diperoleh hasil yang baik. Dari pengamatan organoleptik, tidak terdapat perbedaan dari segi warna dan bau pada setiap formula facial wash gel. Pada Tabel 4 menunjukan pada masingmasing formulasi memiliki kekentalan yang berbeda. Hal ini disebabkan karena perbedaan konsentrasi carbopol sebagai gelling agent yang berbeda. Formulasi 1 dan 2 memiliki kekentalan yang lebih kecil dibandingkan dengan formulasi 3.

Pengujian $\mathrm{pH}$ dilakukan untuk melihat $\mathrm{pH}$ dragon facial wash gel yang dibuat. Hal ini dilakukan karena dragon facial wash gel merupakan sediaan topikal yang digunakan di wajah. Sediaan facial wash gel harus memiliki $\mathrm{pH}$ yang sama dengan pH kulit yaitu 4,5-6,5 (Zhelsiana et al., 2015). Pada tabel 5 hasil yang diperoleh dari pengujian $\mathrm{pH}$ dragon facial wash gel pada formula 1 memiliki nilai $\mathrm{pH}$ yang ideal, yaitu mendekati range $\mathrm{pH}$ balance kulit $(6,46)$, untuk ukuran sediaan topikal (facial wash) dibandingkan dengan formula 2 dan $3 \mathrm{pH}$ di luar range dan tidak mendekati range $\mathrm{pH}$ balance kulit $(6,99-6,68)$ tingginya nilai $\mathrm{pH}$ dragon facial wash gel dapat disebabkan dari pengaruh ekstrak kulit buah naganya sendiri yang mempunyai
pH 4-6 dilihat dari CoA ektrak kulit buah naga tersebut. Hasil analisis statistik $\mathrm{pH}$ pada semua formula dragon facial wash variasi konsentrasi carbopol di uji dengan menggunakan uji one way Anova (uji parametrik) yang menunjukkan nilai sig < 0,05 yang berarti perbedaan konsentrasi carbopol berpengaruh nyata terhadap $\mathrm{pH}$ dragon facial wash gel.

Pemeriksaan tinggi busa merupakan salah satu cara untuk mengetahui apakah suatu deterjen atau surfaktan dapat menghasilkan sediaan yang memiliki kemampuan dalam menimbulkan busa (Saputri et al., 2014). Tidak ada syarat tinggi busa minimum atau maksimum untuk sediaan sabun atau facial wash. Daya busa yang dihasilkan lebih dikaitkan pada nilai estetika yang disukai oleh konsumen, yaitu umumnya konsumen beranggapan bahwa sabun yang baik adalah sabun yang menghasilkan banyak busa, padahal banyaknya busa tidak selalu sebanding dengan kemampuan sabun tersebut untuk membersihkan kotoran (Saputri et al., 2014). Hasil evaluasi tinggi busa dan stabilitas busa pada semua dragon facial wash gel berurut-turut diperoleh dengan kisaran 9,5 cm - 8,43 cm dan 5,8 cm. Dari hasil pengujian tinggi dan stabilitas busa dragon facial wash gel, didapat tinggi dan stabilitas busa masing masing formula 1 $(67.67 \%)$, formula $2(75.83 \%)$ dan 
formula $3(70.53 \%)$. Nilai stabilitas busa tersebut masih memenuhi kriteria stabilitas busa yang baik, yang jika dalam waktu 5 menit diperoleh kisaran stabilitas busa antara 60\% - 70\% (Rozi, 2013). Hasil uji statistik one way Anova terhadap semua formula dragon facial wash gel variasi konsentrasi carbopol menunjukkan nilai sig $<0,05$ yang berarti perbedaan konsentrasi carbopol berpengaruh nyata terhadap tinggi dan stabilitas busa dragon facial wash gel. Peningkatan dan penurunan nilai daya busa disebabkan karena cara pengocokan saat pengujian daya busa menggunakan cara manual, tidak menggunakan alat yang mempunyai standar kecepatan dan waktu yang dapat disesuaikan dengan kebutuhan contohnya seperti magnetic stirer.

Viskositas merupakan suatu parameter untuk melihat kekentalan suatu sediaan. Semakin rendah nilai viskositas maka semakin cepat waktu alir sediaan. Viskositas merupakan karakteristik utama yang berhubungan dengan kemudahan penggunaan sediaan dragon facial wash gel. Carbopol dalam bentuk serbuk merupakan suatu polimer yang membentuk gulungan yang sangat erat (coiled) sehingga hal ini akan membatasi kemampuan thickening-nya, tetapi jika carbopol didispersikan ke dalam air, maka carbopol akan terhidrasi dan beberapa gulungannya akan terbuka (uncoiled)
(Noveon, 2002). Carbopol akan berfungsi dengan baik jika polimer-polimer penyusunnya benar-benar uncoiled. Mekanismenya yaitu penetralan gugus asam karboksilat pada rantai polimer dengan basa yang sesuai. Pembasaan tersebut akan mengakibatkan terbentuknya muatan negatif di sepanjang rantai polimernya, dimana penetralan dilakukan dengan menambahkan TEA. Gaya tolak-menolak antar muatan negatif menyebabkan carbopol akan membuat struktur coiled berubah menjadi struktur yang lebih bebas. Polimer carbopol akan terjalin satu sama lain dengan membentuk cross link sehingga menghasilkan matriks tiga dimensi untuk membentuk gel yang sangat kental dalam waktu seketika (Suhaime et al., 2012), sehingga semakin tinggi nilai viskositas, maka tingkat kekentalan suatu sediaan semakin tinggi pula karena jumlah polimer yang mengalami cross link dan membentuk basis gel semakin banyak. Tidak dapat dikatakan bahwa semakin tinggi viskositas maka sediaan gel semakin baik, karena akan terkait dengan daya sebar dan kenyamanan sediaan selama penggunaan.

Hasil pengukuran viskositas sediaan dragon facial wash gel dapat dilihat pada Tabel 6. Viskositas sediaan gel yang dihasilkan menunjukkan bahwa semakin tinggi konsentrasi carbopol, maka viskositas sediaan semakin 
meningkat. Peningkatan jumlah gelling agent dapat memperkuat matriks penyusun gel sehingga mengakibatkan kenaikan. Hasil uji statistik dengan metode one way Anova menunjukkan bahwa peningkatan carbopol berpengaruh signifikan terhadap penurunan viskositas dragon facial wash gel $(\mathrm{P}<0,05)$.

\section{KESIMPULAN}

Berdasarkan hasil pengujian skrining fitokimia dan sifat fisik yang terdiri dari uji organoleptik, uji $\mathrm{pH}$, uji viskositas masing-masing sediaan memiliki sifat fisik yang baik. Hasil skrining fitokimia ekstrak kulit buah naga (H. polyrhizus) mempunyai senyawa metabolit sekunder yaitu flavonoid, tannin, alkaloid, saponin dan polifenol. Karakteristik dragon facial wash gel yang paling baik di antara ketiga formula dengan variasi konsentrasi carbopol terdapat pada formula I dengan konsentrasi carbopol 1\% dengan memilik sifat fisik, $\mathrm{pH}$, daya busa dan viskositas yang sesuai.

\section{DAFTAR PUSTAKA}

Harborne, JB. 1978. Metode Fitokimia: Penuntun Cara Modern Menganalisis Tumbuhan. Ed II. Diterjemahkan oleh Padmawinata K, Sudiro I, 3-15, Bandung, Institut Teknologi Bandung.
Jaafar, RA., Abdul Rahman, bin AR., Mahmod, NZC., and Vasudevan, R. Proximate Analysis of Dragon Fruit (Hylecereus polyhizus). Am. J. Applied Sci, 2009, 6 (7): 1341-1346.

Melani, D., Purwanti, T., dan Soeratri, W. Korelasi Kadar Propilenglikol dalam Basis dan Pelepasan Dietilammonium Diklofenak dari Basis Gel Carbopol ETD 2020. Majalah Farmasi Airlangga, 2005, 5(1): 5-6.

Manish, K., Tejaswini, S., and Disha, D. Formulation and Evaluation of Anti Acne Face Wash Gel using Guava Seed Extract. Journal of Drug Delivery and Therapeutics, 2019, 9(3): 5-7.

Mitsui, T. 1997. New Cosmetic Science, Dalam Elsevier Science B.V. Amsterdam.

Noveon. 2002. Neutralizing Carbopol ${ }^{\circledR}$ and Pemulen ${ }^{\circledR}$ Polymers in Aqueous and Hydroalcoholic Systems.

http://talasonline.com/photos/msds/ carbopol_mixing.

Rowe, CR., Paul, JS., and Marian E. 2009. Handbook of Pharmaceutical Excipients, Sixth Edition. London Pharmaceutical Press. London.

Rozi, M. 2013. Formulasi Sediaan Sabun (Citrus aurantifolia) dengan Cocamid DEA sebagai Surfaktan. Skripsi. Fakultas Farmasi, Universitas Muhammadiyah Surakarta, Surakarta.

Saputri, W., Radjab, NS., dan Yati K. Perbandingan Optimasi Natrium Lauril Sulfat dengan Optimasi Natrium Lauril Eter Sulfat sebagai Surfaktan Terhadap Sifat Fisik Sabun Mandi Cair Ekstrak Air Kelopak Bunga Rosela (Hibiscus 
sabdariffa L.). Fakultas Farmasi

dan Sains, Universitas Muhammadiyah Prof. DR. Hamka. Jakarta. 1-14.

Suhaime, IHB., Tripathy, M., Mohamed, MS., and Majeed, ABA. The Pharmaceutical Applications of Carbomer. Asian Journal of Pharmaceutical Sciences and Research, 2012, 2(2): 1-12.

Winiarsih, H. 2007. Antioksidan Alami dan Radikal Bebas. Penerbit Kanisius. Yogyakarta.
Wu, LC., Hsu, HW., Chen, YC., Chiu, CC., Lin, YI., and Ho, JAA. Antioxidant and Antiproliferative Activities of Red Pitaya. Food Chemistry, 2006, 95: 319-327.

Zhelsiana, DA., Pangestuti, YS., Nabilla, F., Lestari, NP., dan Wikantyasning, ER. 2016. Formulasi dan Evaluasi Sifat Fisik Masker Gel Peel-Off Lempung Bentonite. The $4^{\text {Th }}$ Univesity Research Coloquium. 4245. 